\title{
Noninvasive Ventilation in Acute Heart Failure
}

\author{
Josep Masip ${ }^{1,2}$
}

Published online: 30 May 2019

(C) Springer Science+Business Media, LLC, part of Springer Nature 2019

\begin{abstract}
Purpose of Review To assess the role of noninvasive ventilation (NIV) in acute heart failure (AHF).

Recent Findings NIV rapidly improves the respiratory distress and reduces the need for intubation and even mortality in patients with acute cardiogenic pulmonary edema (ACPE). Therefore, NIV is indicated as first line therapy in ACPE. NIV may also be considered in some cases of cardiogenic shock after stabilization. CPAP is an easier and cheaper technique that is recommended as first-line therapy, particularly in pre-hospital or low-equipped areas. Noninvasive pressure support ventilation is equally effective in these scenarios, and may be preferable in patients with mild fatigue or significant hypercapnia, including those with associated chronic obstructive pulmonary disease (COPD). High flow nasal cannula is an alternative for patients who need prolonged ventilation or those who show poor tolerance to these techniques.

Summary NIV should be used as a first-line therapy in all patients with ACPE and should be considered in stable cardiogenic shock and AHF associated to COPD.
\end{abstract}

Keywords Noninvasive ventilation $\cdot$ Acute heart failure $\cdot$ CPAP $\cdot$ Pressure support $\cdot$ High-flow nasal cannula

\section{Introduction}

Acute respiratory failure (ARF) is a frequent complication in clinical practice, and it is usually managed with conventional oxygen therapy (COT), mainly high-flow "Venturi" masks, or low-flow reservoir masks and thin nasal cannulas. However, $\mathrm{ARF}$ is not often fully compensated with COT and requires greater respiratory support. Noninvasive ventilation (NIV), a technique that emerged in the 1980s, consisting of the application of positive intrathoracic pressure to conscious patients through different interfaces, has shown to be useful in this setting by reducing the need for EI and invasive mechanical ventilation (IMV) and decreasing some of its associated risks, mainly ventilator-associated pneumonia [1]. Since its introduction, NIV has been extended to different areas of the hospital, the pre-hospital setting and even care at home, while

This article is part of the Topical Collection on Emergency Medicine

Josep Masip

jmasip@ub.edu

1 Intensive Care Department, Consorci Sanitari Integral, University of Barcelona, Jacint Verdaguer 90, ES-08970 Sant Joan

Despí, Barcelona, Spain

2 Cardiology Department, Hospital Sanitas CIMA, Barcelona, Spain
IMV has remained limited to critical units or the operating theater. NIV is currently used to treat ARF in different acute scenarios [2••] (Table 1), having COPD exacerbation and acute cardiogenic pulmonary edema (ACPE) as the strongest indications.

\section{Acute Respiratory Failure in AHF Syndromes}

Although nearly $90 \%$ of acute heart failure (AHF) patients complain of dyspnea [3] and most of them show some degree of lung congestion [4], less than half present ARF with hypoxemia [5]. Among the different AHF scenarios [4, 6, 7], significant ARF is essentially seen in ACPE, in cardiogenic shock (CS), and in cases of AHF associated with other lung alterations.

Acute Cardiogenic Pulmonary Edema Acute cardiogenic pulmonary edema is produced by a rapid increase in pulmonary capillary hydrostatic pressure with fluid filtration that exceeds the lymphatic interstitial drainage capacity [8]. ARF occurs when an excess of interstitial and alveoli flooding results in a significant reduction of gas exchange and a concomitant shunt effect. Therefore, the key findings are the combination of ARF (hypoxemia and/or hypercapnia) with significant 
Table 1 Main indications for NIV in acute respiratory failure

\begin{tabular}{lll}
\hline & Certainty of evidence & Recommendation \\
\hline Hypercapnia with COPD exacerbation & ++++ & Strong \\
Cardiogenic pulmonary edema & +++ & Strong \\
Immunocompromised & +++ & Conditional \\
Post-operative patients & +++ & Conditional \\
Palliative care & +++ & Conditional \\
Trauma & +++ & Conditional \\
Prevention of post-extubation failure in high-risk patients & ++ & Conditional \\
Weaning in hypercapnic patients & +++ & Conditional \\
\hline
\end{tabular}

respiratory distress (tachypnea and increased work of breathing). Criteria for the diagnosis have been recently published [9••] (Table 2) [10, 11]. Patients frequently present hypertension on admission. Hypertensive ACPE more frequently have preserved left ventricular (LV) ejection fraction (EF), hypercapnia, and better prognosis than those with lower blood pressure (BP) [12]. Some of them may have a very rapid

Table 2 Diagnostic criteria for acute pulmonary edema

\begin{tabular}{l}
\hline Clinical criteria (all of them) \\
- Acute respiratory distress ${ }^{\mathrm{a}}$ \\
- Physical examination \\
- Orthopnea \\
- Respiratory failure \\
Diagnostic Confirmation (at least two of the following) \\
- Clear signs of pulmonary congestion on chest radiography or CT scan \\
- Multiple B-lines on lung ultrasound \\
- Elevated pulmonary capillary pressure on catheterization \\
- Increased total lung water on pulse contour and thermodilution \\
analysis system \\
- Signs of elevated filling pressures on echocardiography \\
- Significant elevation of natriuretic peptides
\end{tabular}

$R R$ respiratory rate, $C T$ computer tomography

${ }^{a}$ Respiratory distress: acute increase in the work of breathing (assessed by single inspection), significant tachypnea (RR $>25$ breaths $/$ min) ${ }^{1}$, may be with the use of accessory muscles or abdominal paradox

${ }^{\mathrm{b}}$ Crackles + - - wheezes over the lungs, third heart sound ${ }^{2}$

${ }^{\mathrm{c}}$ Oxygen saturation on room air by pulse-oximetry $\left(\mathrm{SpO}_{2}\right)<90 \%$. Arterial blood gases may also show $\mathrm{PaO} 2<60 \mathrm{mmHg}, \mathrm{PaCO} 2>$ $45 \mathrm{mmHg}$, or $\mathrm{PaO}_{2} / \mathrm{FiO}_{2}<300 \mathrm{mHg}$

${ }^{d} \geq 3$ B-lines in 2 chest zones on each hemithorax (references 7,8)

${ }^{\mathrm{e}} \mathrm{E} / \mathrm{E}^{\prime}>15$. Other parameters of elevated left atrial pressure may also be considered

${ }^{\mathrm{f}} \mathrm{Nt}$-ProBNP $>900$ (or $>1800$ in older than 75)

${ }^{1} \mathrm{RR}$ may be lower, and orthopnea may be absent in obtunded patients

${ }^{2}$ Patients with low systolic blood pressure (i.e., $<90 \mathrm{mmHg}$ ) may be considered to have cardiogenic shock rather than ACPE

${ }^{3}$ In "flash pulmonary edema," BNP may be lower

(Taken from reference 9 in the text) presentation, "flash ACPE," without previous accumulation of fluids and mostly diastolic LV dysfunction [13].

Cardiogenic Shock Patients have significant ARF for several reasons. There are pulmonary edema and ventilationperfusion inequality due to an increase in pulmonary dead space due to a fall of lung perfusion. In addition, the circulatory failure reduces the central venous oxygen content $\left(\mathrm{SvO}_{2}\right)$ secondary to a greater tissue extraction.

Other Scenarios Patients with AHF may also have COPD, pneumonia, asthma, large pleural effusion, pulmonary embolism, or atelectasis, which may precipitate or aggravate ARF. In cases with isolated right ventricular (RV) failure, ARF is mainly seen in cases of acute pulmonary thromboembolism or decompensated chronic pulmonary hypertension.

\section{Effect of NIV in AHF}

Positive airway pressure increases oxygenation and decreases the work of breathing [14]. Ventilatory support additionally improves alveolar ventilation with further decreases in the work of breathing and carbon dioxide level [15]. NIV has shown to produce faster improvement of the ARF, shortening the critical phase, decreasing the risk of endotracheal intubation, and, potentially, reducing mortality in high-risk patients. However, in patients with isolated RV failure, positive pressure should be avoided because it increases RV afterload, impairing RV function [16].

\section{Modalities of NIV}

The main modalities in AHF are continuous positive airway pressure (CPAP), noninvasive pressure support ventilation (NIPSV), and, more recently, high-flow nasal cannula (HFNC).

CPAP CPAP is the simplest technique and consists of the application of a high flow in the mask exceeding the breathing demand of the patients, leading to a continuous positive pressure 
into the lungs. It can be applied without the aid of a ventilator, by using a source of air or oxygen and a mask equipped with PEEP valve, or with the Boussignac system [17].

NIPSV This modality requires a ventilator. It is programmed with two levels of pressure: expiratory pressure (EPAP) or positive end-expiratory pressure (PEEP), and inspiratory pressure (IPAP), which is obtained with pressure support. It is also called noninvasive intermittent positive pressure ventilation (NIPPV), or sometimes bilevel or BiPAP. This method requires some experience for setting the ventilator to the changing needs of the patient. Adequate synchrony is essential. The respiratory rate is not pre-set and depends exclusively on the patient.

High-Flow Nasal Cannula This system delivers a heated and humidified high flow (up to $60-80 \mathrm{~L} / \mathrm{min}$ ) that exceeds patients' spontaneous inspiratory demand through a nasal cannula adjusted to the nostrils (Fig. 1). The technique provides three beneficial effects: first, a low level of PEEP $\left(<5 \mathrm{cmH}_{2} \mathrm{O}\right)$ that requires closed mouth [18] which could be a disadvantage in cases of severe dyspnea like ACPE where the patients generally breath by the mouth; second, a washout effect in nasopharyngeal, which may reduce $\mathrm{CO} 2$ in the dead space, like tracheal gas insufflation; third, a reduction of the upper airway resistance [19].

\section{Evidence for the Use of NIV in AHF Syndromes}

\section{CPAP and NIPSV in ACPE}

Several small randomized trials performed at the end of the 1980s using CPAP showed faster improvement of ARF than

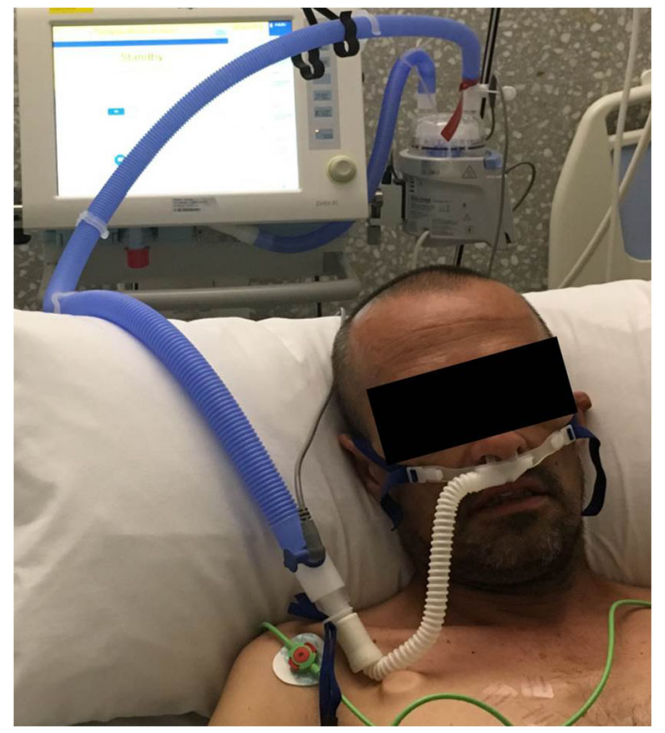

Fig. 1 High-flow nasal cannula administered through a ventilator
COT $[20,21]$ with a reduction in the endotracheal intubation (EI) rate [21]. The first randomized trial of NIPSV in ACPE, published in 2000, showed similar results [22]. Several metaanalyses [23-25] revealed both techniques reduced the EI rate and tended to reduce mortality as compared with COT, a trend that was statistically significant for CPAP. However, in 2008, a large randomized trial (3-CPO) including 1069 patients with acidotic ( $\mathrm{pH}<7.35$ ) ACPE assigned to CPAP, NIPSV, or COT [26] showed no difference in mortality, although both NIV techniques improved respiratory distress faster than COT. Differences in the population [27] and a high intergroup crossover rate using NIV as a rescue therapy could explain the discrepancy with meta-analyses. However, subsequent metaanalyses including this trial showed that both modalities reduced the EI rate and still, CPAP reduced mortality (relative risk 0.64 [95\% CI, 0.44 to 0.92 ]), mainly in high-risk patients with acute coronary syndromes [28, 29].

Several studies have shown beneficial effects of the early application of CPAP in the pre-hospital care of patients with ACPE, improving ARF faster than COT, with a tendency to reduce the EI rate [30-32]. Because CPAP does not require special training or expensive equipment, it can be the recommended technique in this setting.

\section{HFNC in AHF}

In adults, HFNC has recently shown to be effective in the weaning of patients from mechanical ventilation [33, 34] and in hypoxemic RF from different etiologies [35].

In AHF, the data is scarce, with only one small randomized study published in 2017 showing a greater decrease in respiratory rate after $60 \mathrm{~min}$ without differences in all other parameters [36••]. HFNC has been used in class III patients [37] and in AHF patients needing prolonged ventilation support [38]. HFNC seems to be better tolerated than NIPSV [39] and subsequently is showing an expansion of the technique [40•].

\section{Other Modalities of NIV in AHF}

Other techniques like proportional assist ventilation or adapted servoventilation have been used in some trials in patients with ACPE without showing an impact in the main outcomes [41, 42].

\section{Other Scenarios of AHF Where NIV Can Be Used}

NIV is not indicated in patients with AHF not showing significant respiratory distress and ARF, which are most of the patients with AHF. As aforementioned, positive pressure should be avoided in patients with isolated RV failure [16]. However, in cases with ARF of mixed origin (COPD with pulmonary edema), NIV may be especially useful because it may benefit both underlying conditions [43]. 


\section{NIV and Myocardial Infarction}

Two trials in the 1990s suggested that NIPSV could increase the risk of acute myocardial infarction (AMI) [44, 45]. However, no other trial has reproduced these results, including randomized studies specifically designed to assess this issue [46-48]. One randomized trial analyzed the effect of CPAP in patients with AMI showing advantages over COT [49]. In addition, in 3-CPO, NIV was safely used in patients with AMI, who accounted for nearly $50 \%$ of the population enrolled, with no differences in the incidence of AMI between groups [26].

\section{NIV in Cardiogenic Shock}

There are no studies analyzing NIV in CS. However, in the international registry "Cardshock study" [50], NIV was used in nearly $13 \%$ of the patients, after correction of hypotension, avoiding EI in the majority [51••]. Therefore, although the indication of NIV remains limited in hypotensive patients, it may be cautiously considered in selected CS patients.

\section{CPAP or NIPSV}

Although theoretically NIPSV should be superior to CPAP because it provides inspiratory help for breathing, no trials or meta-analyses have demonstrated a clear advantage of one technique over the other for important outcomes but patients treated with NIPSV have shown faster improvement in several physiological variables $[45,52,53]$. In several case series of patients with ACPE, NIPSV was most clearly effective in those with hypercapnia [22, 54]. In addition, in patients with ARF from different etiologies, CPAP has been most often used in hypoxemic patients, while NIPSV may be more effective in those with hypercapnia. Consequently, although either technique can be used as a first-line treatment in ACPE, it seems reasonable to prefer NIPSV in patients with severe hypercapnia, including those with COPD.

\section{Recommendations for NIV in AHF}

NIV has shown an expansion in the last decades, particularly in ACPE [55 ${ }^{\circ}$; however, there is a wide variation among centers, from nearly 0 to almost $100 \%$ [56]. ACPE is currently the second most frequent indication for NIV [57]. Data from 2430 patients who required ventilatory support in the ADHERE registry supported the use of NIV to avoid EI [15]. The latest ESC guidelines gave NIV a class IIa recommendation with level of evidence B $[58,59]$ in patients with AHF and respiratory distress (respiratory rate $>25$ breaths/ min, $\mathrm{SpO} 2<90 \%$ ). The NICE guidelines in AHF recommended NIV in patients with ACPE with severe dyspnea and acidemia [60]. Finally, recent guidelines from ERC/ATS recommended NIV, either bilevel NIV or CPAP, for patients with ARF due to ACPE and suggested it in the pre-hospital setting $[2 \cdot \bullet]$.

Figure 2 shows a recently proposed algorithm for the use of NIV in the management of patients with AHF [61-63].

\section{How to Use NIV}

It is important to choose the appropriate interface. In order to avoid leaks, a tight seal between the patient's face and the device is essential. There are different types of interfaces, mainly masks (oro-nasal, total-face, full-face, and nasal), helmet, or nasal cannulas (see Fig. 3) [64]. Other interfaces like nasal pillows, mouthpieces, or laryngeal masks are not considered in AHF. Total-face mask and helmet provide better patients' adaptation.

There are three types of ventilators: portable, transport, and ICU-ventilators, all equipped with specific settings for CPAP and NIPSV. The latest generation of ventilators are equipped with display monitoring, alarm setting, leakage compensation, different triggers, cycling, and flow ramp control, which allow the achievement of a better patient-ventilator synchrony [65]. Skin protectors and heat humidification or heat and moisture exchangers may be useful [66].

Before starting the technique, contraindications for NIV should be considered (Table 3).

For NIPSV, low levels of pressure (IPAP $10-12 \mathrm{cmH}_{2} \mathrm{O} /$ EPAP 3-4 $\mathrm{cmH}_{2} \mathrm{O}$ ) are recommended to start with, increasing PS progressively according to how well the patient has adapted, ensuring expired tidal volumes $>4-6 \mathrm{~mL} / \mathrm{kg}$ (pressure can be lower in COPD patients). High pressures may cause excessive air leakage, asynchrony (especially in patients with high RR), and discomfort.

When using CPAP, it is advisable to start with $5 \mathrm{cmH}_{2} \mathrm{O}$ and increase to 7.5 or $10 \mathrm{cmH}_{2} \mathrm{O}$, according to the response.

When using HFNC in critically ill patients, it is often started with a $\mathrm{F}_{\mathrm{I}} \mathrm{O}_{2}$ of $100 \%$ and the maximum tolerated flow up to $50 \mathrm{~L} / \mathrm{min}$, titrating later $\mathrm{F}_{\mathrm{I}} \mathrm{O}_{2}$ and flow rate according to $\mathrm{SpO}_{2}$ [18] and patient's demand. In less severe cases, it is usually started with lower flow and $\mathrm{F}_{\mathrm{I}} \mathrm{O}_{2}$.

During the application of NIV, besides standard physiologic parameters, RR (patient's effort), oxygen saturation (minimal required $\mathrm{F}_{\mathrm{I}} \mathrm{O}_{2}$ ), and $\mathrm{pH} / \mathrm{PaCO}_{2}$ (to assess efficacy) should be monitored. General reassessment is recommended at 60 and/or 90-120 min. The key issue is optimal synchronization with the ventilator [67-69]. Excessive leakage is often involved in cases of asynchrony, which may be reduced by adjusting the mask, shortening inspiration time, giving sedation, reducing PS, or changing inspiratory and expiratory triggers (when available). In general, a leak $<0.4 \mathrm{~L} / \mathrm{s}$ may be tolerated $(<25 \mathrm{~L} / \mathrm{min})$. 

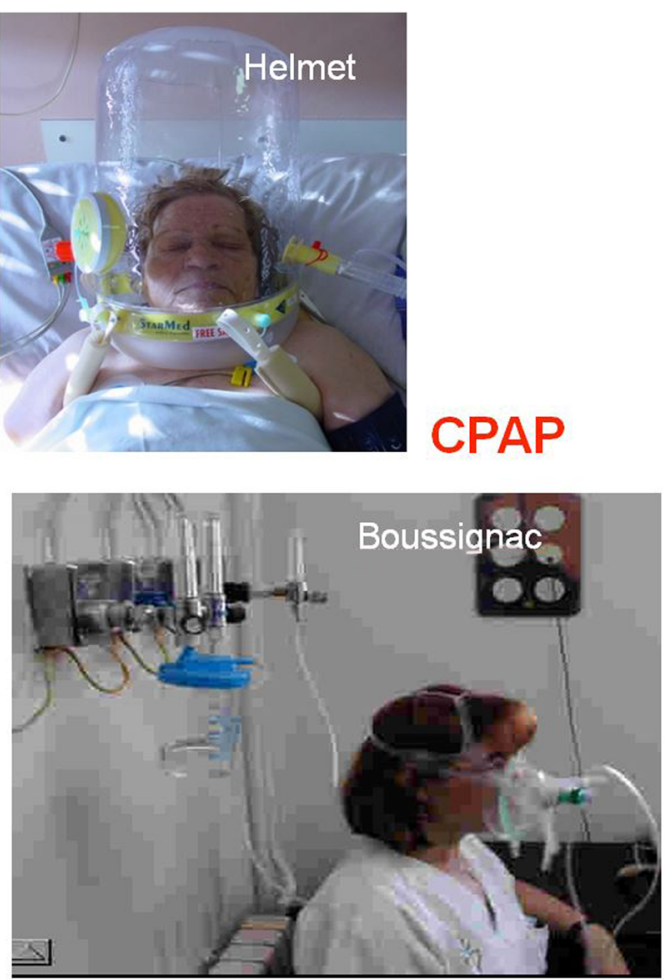

Fig. 2 Algorithm for the use of NIV in AHF (taken from reference 9)

Sedation Mild sedation is used nearly in $20 \%$ of the patients treated with NIV to decrease RR and intolerance [70-72]. It should be used only when patients show poor synchrony with
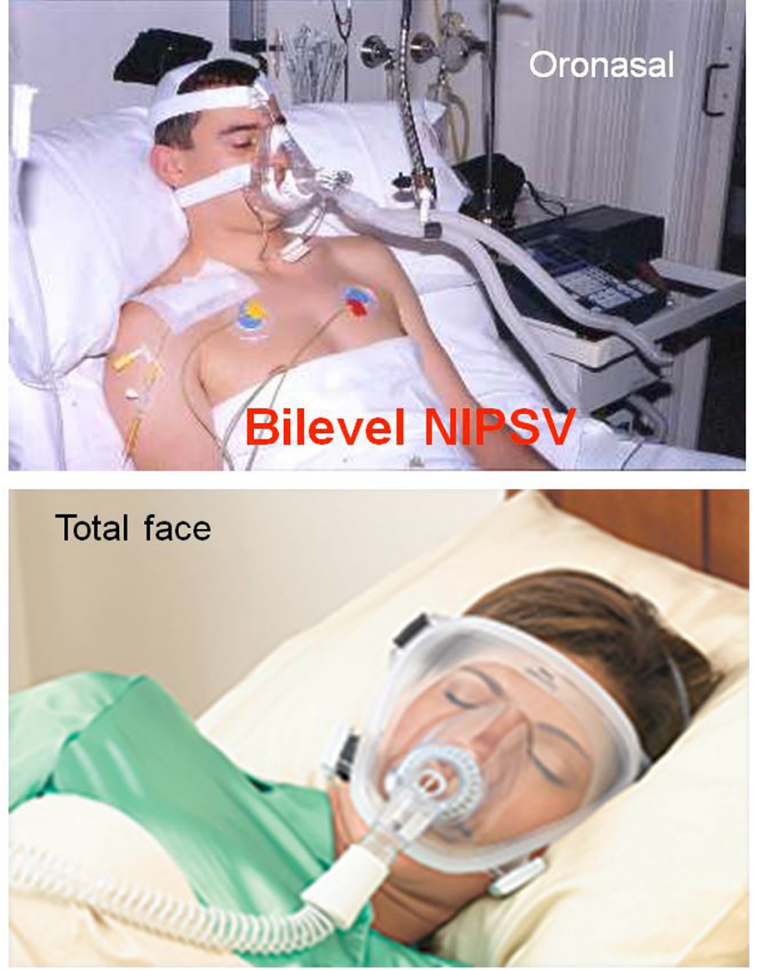

the ventilator after nonpharmacological approaches have failed [73, 74]. Minimal intermittent doses of a single drug may be preferable to continuous infusions or combinations of

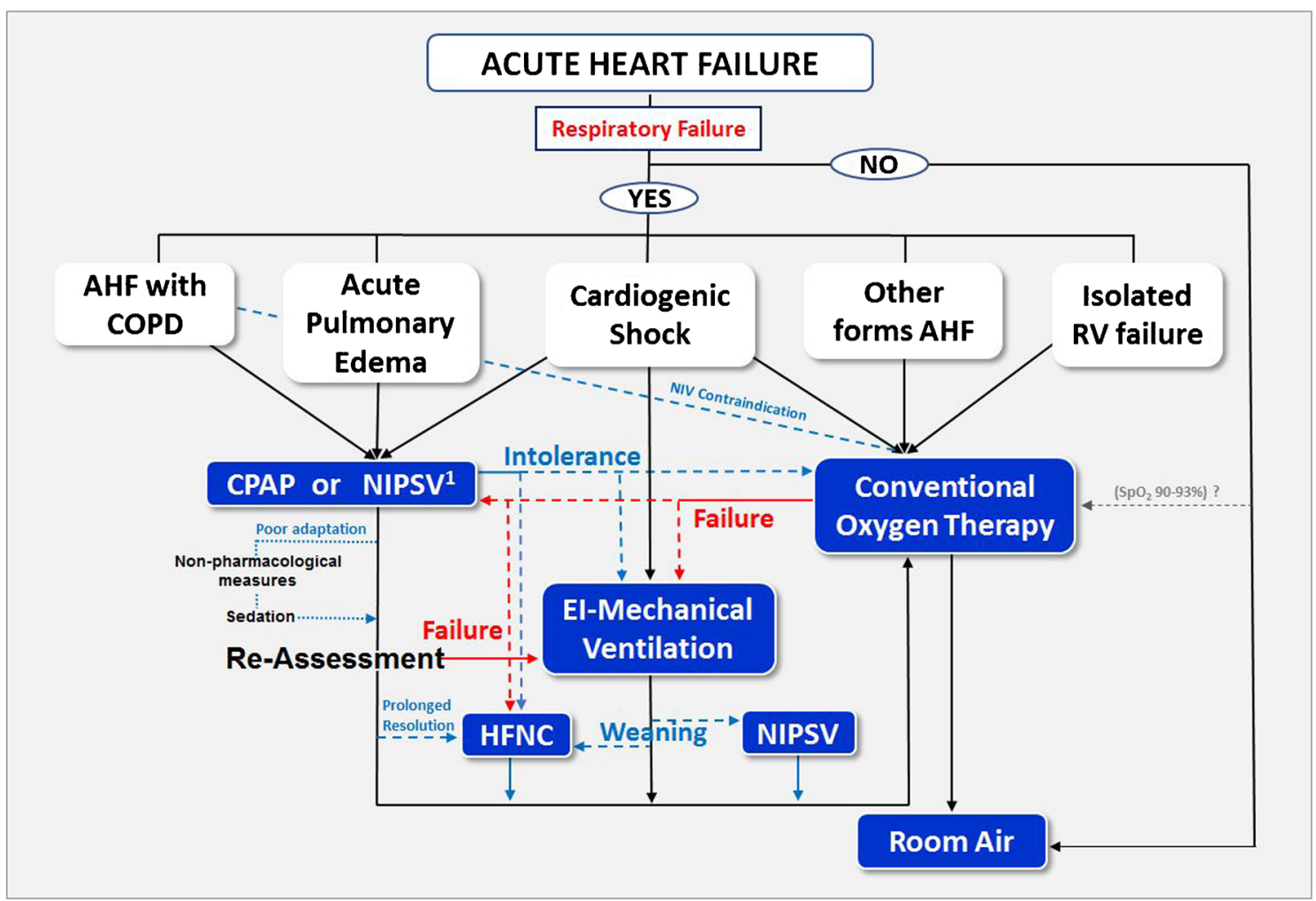

Fig. 3 Different interfaces used to treat patients with AHF 
Table 3 Contraindications of NIV

\begin{tabular}{ll}
\hline Absolute & Cardiac or respiratory arrest \\
& Anatomical abnormality (unable to fit the interface) \\
& Inability to keep patent airway (uncontrolled agitation, coma ${ }^{1}$, or obtunded mental status) \\
& Refractory hypotension \\
& Mild agitation or poor cooperation \\
& Mild hypotension \\
& Upper gastrointestinal hemorrhage or vomiting \\
& Inability to expectorate copious secretions \\
& Recent frail upper gastrointestinal or airway surgery \\
& Severe multi-organ failure \\
& Isolated right ventricular failure
\end{tabular}

${ }^{1}$ Modalities like NIV with volume controlled or "average volume assured pressure support" have been used in hypercapnic encephalopathy different agents $[62,63]$. Opiods (morphine, remifentanil), propofol, midazolam, and more recently dexmedetomidine have been used in this context $[63,64]$.

NIV is usually stopped when a satisfactory recovery has been achieved (usually $2-5 \mathrm{~h}$ in ACPE) or conversely, there are signs of NIV failure, requiring EI (Table 4). With $\mathrm{F}_{\mathrm{I}} \mathrm{O}_{2}<0.5$ and flow rate $<20 \mathrm{~L} / \mathrm{m}$, HFNC can be safely replaced by COT.

\section{Conclusions}

In patients with ACPE, NIV improves faster and more effectively respiratory distress than conventional oxygen therapy, reducing the need for EI and mortality in severe cases as are those with ACS. Therefore, it should be used as a first-line therapy in all patients with ACPE. It can also be used in some
Table 4 Risk factors for NIV failure and criteria for endotracheal intubation
Risk factors for NIV failure
Before initiation:

After initiation:

After 60-90 min:

Criteria for endotracheal intubation

Cardiac or respiratory arrest

Progressive worsening of altered mental status

Progressive worsening of $\mathrm{pH}, \mathrm{PaCO}_{2}$, or $\mathrm{PaO}_{2}$ despite NIV

Progressive signs of fatigue during NIV

Need to protect the airway

Persistent hemodynamic instability

Agitation or intolerance to NIV with progressive respiratory failure 
patients with cardiogenic shock without refractory hypotension and in patients with AHF associated with lung disease showing ARF. CPAP is cheaper and easy to use, and it is mainly indicated in low-equipped areas, whereas NIPSV is preferred in cases with significant hypercapnia, although requires some expertise and adequate setting. HFNC may be considered in patients with ARF who can keep the mouth closed and require prolonged ventilation or not tolerating other forms of NIPSV.

\section{Compliance with Ethical Standards}

Conflict of Interest The author declares that he has no conflicts of interest.

Human and Animal Rights and Informed Consent This article does not contain any studies with human or animal subjects performed by any of the authors.

\section{References}

Papers of particular interest, published recently, have been

highlighted as:

- Of importance

•. Of major importance

1. Girou E, Brun-Buisson C, Taillé S, Lemaire F, Brochard L. Secular trends in nosocomial infections and mortality associated with noninvasive ventilation in patients with exacerbation of COPD and pulmonary edema. JAMA. 2003;290:2985-91.

2.• Rochwerg B, Brochard L, Elliott MW, Hess D, Hill NS, Nava S, et al. Official ERS/ATS clinical practice guidelines: noninvasive ventilation for acute respiratory failure. Eur Respir J. 2017;50: 1602426. https://doi.org/10.1183/13993003.02426-2016 Analyzes the evidence of the usefulness of NIV in the most frequent different acute respiratory failure scenarios and provides different levels of recommendation.

3. Mebazaa A, Pang PS, Tavares M, Collins SP, Storrow AB, Laribi S, et al. The impact of early standard therapy on dyspnoea in patients with acute heart failure: the URGENT-dyspnoea study. Eur Heart J. 2010;31:832-41.

4. Dickstein K, Cohen-Solal A, Filippatos G, McMurray JJ, Ponikowski P, Poole-Wilson PA, et al. ESC guidelines for the diagnosis and treatment of acute and chronic heart failure 2008: the task force for the diagnosis and treatment of acute and chronic heart failure 2008 of the European Society of Cardiology. Eur Heart J. 2008;29:2388-442.

5. Park JJ, Choi DJ, Yoon CH, Oh IY, Lee JH, Ahn S, et al. The prognostic value of arterial blood gas analysis in high-risk acute heart failure patients: an analysis of the Korean Heart Failure (KorHF) registry. Eur J Heart Fail. 2015;17:601-11.

6. Nieminen MS, Böhm M, Cowie MR, Drexler H, Filippatos GS, Jondeau G, et al. Executive summary of the guidelines on the diagnosis and treatment of acute heart failure. The task force on acute heart failure of the European Society of Cardiology endorsed by the European Society of Intensive Care Medicine (ESICM). Eur Heart J. 2005;26:384-416.

7. Chioncel O, Mebazaa A, Harjola V-P, Coats AJ, Piepoli MF, Crespo-Leiro MG, et al. Clinical phenotypes and outcome of patients hospitalized for acute heart failure: the ESC Heart Failure Long-Term Registry. Eur J Heart Fail. 2017;19:1242-54.

8. Ware LB, Matthay MA. Clinical practice. Acute pulmonary edema. N Engl J Med. 2005;353:2788-96.

9.• Masip J, Peacock WF, Price S, Cullen L, Martin-Sanchez FJ, Seferovic $\mathrm{P}$, et al. Indications and practical approach to noninvasive ventilation in acute heart failure. Eur Heart J. 2018;39:17-25 This is a position paper from two AHF working groups of the ESC. The review describes the main AHF phenotypes showing ARF and analyzes the evidence of NIV on each one of them. Indications and practical recommendations are also provided.

10. Volpicelli G, Elbarbary M, Blaivas M, Lichtenstein DA, Mathis G, Kirkpatrick AW, et al. International evidence-based recommendations for point-of-care lung ultrasound. Intensive Care Med. 2012;38:577-91.

11. Pivetta E, Goffi A, Lupia E, Tizzani M, Porrino G, Ferreri E, et al. Lung ultrasound-implemented diagnosis of acute decompensated heart failure in the ED: a SIMEU multicenter study. Chest. 2015;148:202-10.

12. Figueras J, Bañeras J, Peña-Gil C, Masip J, Barrabés JA, Rodriguez Palomares $\mathrm{J}$, et al. Acute arterial hypertension in acute pulmonary edema. Mostly a trigger or an associated phenomenon? Can J Cardiol. 2016:32:1214-20.

13. Kramer K, Kirkman P, Kitzman D, Little WC. Flash pulmonary edema: association with hypertension and reoccurrence despite coronary revascularization. Am Heart J. 2000;140:451-5.

14. Tobin MJ. Advances in mechanical ventilation. N Engl J Med. 2001;344:1986-96.

15. Tallman TA, Peacock WF, Emerman CL, Lopatin M, Blicker JZ, Weber J, et al. Noninvasive ventilation outcomes in 2,430 acute decompensated heart failure patients: an ADHERE registry analysis. Acad Emerg Med. 2008;15:355-62.

16. Harjola VP, Mebazaa A, Čelutkienè J, Bettex D, Bueno H, Chioncel $\mathrm{O}$, et al. Contemporary management of acute right ventricular failure: a statement from the heart failure association and the working group on pulmonary circulation and right ventricular function of the European Society of Cardiology. Eur J Heart Fail. 2016;18:226-41.

17. Moritz F, Benichou J, Vanheste M, Richard JC, Line S, Hellot MF, et al. Boussignac continuous positive airway pressure device in emergency care of acute cardiogenic pulmonary oedema: a randomized pilot study. Eur J Emerg Med. 2003;10:204-8.

18. Luo J-c, Lu M-s, Zhao Z-h, Jiang W, Xu B, Weng L, et al. Positive end-expiratory pressure effect of 3 high-flow nasal cannula devices. Respir Care. 2017;62:888-95.

19. Lee JH, Rehder KJ, Williford L, Cheifetz IM, Turner DA. Use of high flow nasal cannula in critically ill infants, children, and adults: a critical review of the literature. Intensive Care Med. 2013;39:24757.

20. Räsänen J, Heikklä J, Downs J, Nikki P, Väisänen I, Viitanen A. Continuous positive airway pressure by face mask in acute cardiogenic pulmonary edema. Am J Cardiol. 1985;55:296-300.

21. Bersten AD, Holt AW, Vedig AE, Skowronski GA, Baggoley CJ. Treatment of severe cardiogenic pulmonary edema with continuous positive airway pressure delivered by face mask. N Engl J Med. 1991;325:1825-30.

22. Masip J, Betbesé AJ, Páez J, Vecilla F, Cañizares R, Padró J, et al. Non-invasive pressure support ventilation versus conventional oxygen therapy in acute cardiogenic pulmonary oedema: a randomized trial. Lancet. 2000;356:2126-32.

23. Peter JV, Moran JL, Phillips-Hughes J, Graham P, Bersten AD. Effect of non-invasive positive pressure ventilation (NIPPV) on mortality in patients with acute cardiogenic pulmonary oedema: a meta-analysis. Lancet. 2006;367:1155-63.

24. Masip J, Roque M, Sánchez B, Fernández R, Subirana M, Expósito $\mathrm{J}$. Noninvasive ventilation in acute cardiogenic pulmonary edema. Systematic review and meta-analysis. JAMA. 2005;294:3124-30. 
25. Winck J, Azevedo LF, Costa-Pereira A, Antonelli M, Wyatt JC. Efficacy and safety of non-invasive ventilation in the treatment of acute cardiogenic pulmonary edema: a systematic review and metaanalysis. Crit Care. 2006;10:R69.

26. Gray A, Goodacre S, Newby DE, Masson M, Sampson F, Nicholl J, et al. Noninvasive ventilation in acute cardiogenic pulmonary edema. N Engl J Med. 2008;359:142-51.

27. Masip J, Mebazaa A, Filippatos G. Noninvasive ventilation in acute cardiogenic pulmonary edema. N Engl J Med. 2008;359:2068-9.

28. Weng CL, Zhao YT, Liu QH, Fu CJ, Sun F, Ma YL, et al. Metaanalysis: noninvasive ventilation in acute cardiogenic pulmonary edema. Ann Intern Med. 2010;152:590-600.

29. Masip J, Páez J, Merino M, Parejo S, Vecilla F, Riera C, et al. Risk factors for intubation as a guide for noninvasive ventilation in patients with severe acute cardiogenic pulmonary edema. Intensive Care Med. 2003;29:1921-8.

30. Ducros L, Logeart D, Vicaut E, Henry P, Plaisance P, Collet JP, et al. CPAP for acute cardiogenic pulmonary oedema from out-ofhospital to cardiac intensive care unit: a randomised multicentre study. Intensive Care Med. 2011;37:1501-9.

31. Plaisance P, Pirracchio R, Berton C, Vicaut E, Payen D. A randomized study of out-of-hospital continuous positive airway pressure for acute cardiogenic pulmonary oedema: physiological and clinical effects. Eur Heart J. 2007;28:2895-901.

32. Foti G, Sangalli F, Berra L, Sironi S, Cazzaniga M, Rossi GP, et al. Is helmet CPAP first line pre-hospital treatment of presumed severe acute pulmonary edema? Intensive Care Med. 2009;35:656-62.

33. Hernández G, Vaquero C, Colinas L, Cuena R, González P, Canabal A, et al. Effect of Postextubation high-flow nasal cannula vs noninvasive ventilation on reintubation and Postextubation respiratory failure in high-risk patients: a randomized clinical trial. JAMA. 2016;316:1565-74.

34. Hernández G, Vaquero C, González P, Subira C, Frutos-Vivar F, Rialp G, et al. Effect of postextubation high-flow nasal cannula vs conventional oxygen therapy on reintubation in low-risk patients: a randomized clinical trial. JAMA. 2016;315:1354-61.

35. Frat JP, Thille AW, Mercat A, Girault C, Ragot S, Perbet S, et al. High-flow oxygen through nasal cannula in acute hypoxemic respiratory failure. N Engl J Med. 2015;372:2185-96.

36.• Makdee O, Monsomboon A, Surabenjawong U, Praphruetkit N, Chaisirin W, Chakorn T, et al. High-flow nasal cannula versus conventional oxygen therapy in emergency department patients with cardiogenic pulmonary edema: a randomized controlled trial. Ann Emerg Med. 2017;70:465-72 This is the first trail analyzing the effect of HFNC in ACPE compared with conventional oxygen therapy. No significant differences in the outcomes were found, but the study showed a decrease in respiratory rate in the first hour with HFNC.

37. Roca O, Pérez-Terán P, Masclans JR, Pérez L, Galve E, Evangelista A, et al. Patients with New York Heart Association class III heart failure may benefit with high flow nasal cannula supportive therapy. High flow nasal cannula in heart failure. J Crit Care. 2013;28:7416.

38. Carratalá JM, Llorens P, Brouzet B, Albert AR, Fernández-Cañadas $\mathrm{JM}$, Carbajosa J, et al. High-flow therapy via nasal cannula in acute heart failure. Rev Esp Cardiol. 2011;64:723-35.

39. Frat JP, Brugiere B, Ragot S, Chatellier D, Veinstein A, Goudet V, et al. Sequential application of oxygen therapy via high-flow nasal cannula and noninvasive ventilation in acute respiratory failure: an observational pilot study. Respir Care. 2015;60:170-8.

40. Corley A, Rickard CM, Aitken LM, Johnston A, Barnett A, Fraser JF, et al. High-flow nasal cannulae for respiratory support in adult intensive care patients. Cochrane Database Syst Rev. 2017;5: CD010172 Analyzes the studies assessing the effect of HFNC in acute respiratory failure and concludes that there is no enough evidence of the superiority of HFNC compared with conventional oxygen or classical forms of NIV.

41. Rusterholtz T, Bollaert PE, Feissel M, Romano-Girard F, Harlay ML, Zaehringer M, et al. Continuous positive airway pressure vs. proportional assist ventilation for noninvasive ventilation in acute cardiogenic pulmonary edema. Intensive Care Med. 2008;34:840 6.

42. Nakano S, Kasai T, Tanno J, Sugi K, Sekine Y, Muramatsu T, et al. The effect of adaptive servo-ventilation on dyspnoea, haemodynamic parameters and plasma catecholamine concentrations in acute cardiogenic pulmonary oedema. Eur Heart J Acute Cardiovasc Care. 2015;4:305-15.

43. Cabrini L, Landoni G, Oriani A, Plumari VP, Nobile L, Greco M, et al. Noninvasive ventilation and survival in acute care settings: a comprehensive systematic review and metaanalysis of randomized controlled trials. Crit Care Med. 2015;43:880-8.

44. Mehta S, Jay GD, Woolard RH, Hipona RA, Connolly EM, Cimini $\mathrm{DM}$, et al. Randomized, prospective trial of bilevel versus continuous positive airway pressure in acute pulmonary edema. Crit Care Med. 1997;25:620-8.

45. Sharon A, Shpirer I, Kaluski E, Moshkovitz Y, Milovanov O, Polak $\mathrm{R}$, et al. High-dose intravenous isosorbide-dinitrate is safer and better than Bi-PAP ventilation combined with conventional treatment for severe pulmonary edema. J Am Coll Cardiol. 2000;36: 832-7.

46. Bellone A, Monari A, Cortellaro F, Vettorello M, Arlati S, Coen D. Myocardial infarction rate in acute pulmonary edema: noninvasive pressure support ventilation versus continuous positive airway pressure. Crit Care Med. 2004;32:1860-5.

47. Yamamoto T, Takeda S, Sato N, Akutsu K, Mase H, Nakazato K, et al. Noninvasive ventilation in pulmonary edema complicating acute myocardial infarction. Circ J. 2012;76:2586-91.

48. Ferrari G, Olliveri F, De Filippi G, et al. Noninvasive positive airway pressure and risk of myocardial infarction in acute cardiogenic pulmonary edema: continuous positive airway pressure vs noninvasive positive pressure ventilation. Chest. 2007;132:1804-9.

49. Takeda S, Nejima J, Takano T, Nakanishi K, Takayama M, Sakamoto A, et al. Effect of nasal continuous positive airway pressure on pulmonary edema complicating acute myocardial infarction. Jpn Circ J. 1998;62:553-38.

50. Harjola VP, Lassus J, Sionis A, Køber L, Tarvasmäki T, Spinar J, et al. CardShock study investigators; GREAT network. Clinical picture and risk prediction of short-term mortality in cardiogenic shock. Eur J Heart Fail. 2015;17:501-9.

51.• Hongisto M, Lassus J, Tarvasmaki T, Sionis A, Tolppanen H, Lindholm MG, et al. Use of noninvasive and invasive mechanical ventilation in cardiogenic shock: a prospective multicenter study. Int J Cardiol. 2016;230:191-7. This is the first and the only published article that addresses this issue.

52. Park M, Lorenzi-Filho G, Feltrim MI, Viecili PR, Sangean MC, Volpe M, et al. Oxygen therapy, continuous positive airway pressure, or noninvasive bilevel positive pressure ventilation in the treatment of acute cardiogenic pulmonary edema. Arq Bras Cardiol. 2001;76:221-30.

53. Liesching T, Nelson DL, Cormier KL, Sucov A, Short K, Warburton R, et al. Randomized trial of bilevel versus continuous positive airway pressure for acute pulmonary edema. J Emerg Med. 2014:46:130-40.

54. Nava S, Carbone G, DiBattista N, Bellone A, Baiardi P, Cosentini $R$, et al. Noninvasive ventilation in cardiogenic pulmonary edema: a multicenter randomized trial. Am J Respir Crit Care Med. 2003;168:1432-7.

55. Demoule A, Chevret S, Carlucci A, Kouatchet A, Jaber S, Meziani $\mathrm{F}$, et al. Changing use of noninvasive ventilation in critically ill patients: trends over 15 years in francophone countries. Intensive 
Care Med. 2016;42:82-92. This one of the largest and recent registries analyzing the use of NIV in the last $\mathbf{1 5}$ years.

56. Kulkarni VT, Kim N, Dai Y, Dharmarajan K, Safavi KC, Bikdeli B, et al. Hospital variation in noninvasive positive pressure ventilation for acute decompensated heart failure. Circ Heart Fail. 2014;7:42733.

57. Burns KE, Sinuff T, Adhikari NK, Meade MO, Heels-Ansdell D, Martin CM. Bilevel noninvasive positive pressure ventilation for acute respiratory failure: survey of Ontario practice. Crit Care Med. 2005;33:1477-83.

58. Ponikowski P, Voors AA, Anker SD, Bueno H, Cleland JG, Coats AJ, et al. 2016 ESC guidelines for the diagnosis and treatment of acute and chronic heart failure. Eur Heart J. 2016;37:2129-200.

59. McMurray JJ, Adamopoulos S, Anker SD, Auricchio A, Böhm M, Dickstein K, et al. ESC guidelines for the diagnosis and treatment of acute and chronic heart failure 2012: the task force for the diagnosis and treatment of acute and chronic heart failure 2012 of the European Society of Cardiology. Developed in collaboration with the Heart Failure Association (HFA) of the ESC. Eur Heart J. 2012;33:1787-847.

60. National Clinical Guideline Centre (UK). Acute heart failure. diagnosing and managing acute heart failure in adults. London: National Institute for Health and Care Excellence (UK); 2014.

61. Mebazaa A, Yilmaz MB, Levy P, Ponikowski P, Peacock WF, Laribi S, et al. Recommendations on pre-hospital \& early hospital management of acute heart failure: a consensus paper from the Heart Failure Association of the European Society of Cardiology, the European Society of Emergency Medicine and the Society of Academic Emergency Medicine. Eur J Heart Fail. 2015;17:544-58.

62. Mebazaa A, Yilmaz MB, Levy P, Ponikowski P, Peacock WF, Laribi S, et al. Recommendations on pre-hospital \& early hospital management of acute heart failure: a consensus paper from the heart failure Association of the European Society of cardiology, the European Society of Emergency Medicine and the Society of Academic Emergency Medicine - Short version. Eur Heart J. 2015;36:1958-66.

63. Mueller C, Christ M, Cowie M, Cullen L, Maisel AS, Masip J, et al. European Society of Cardiology-acute cardiovascular care association position paper on acute heart failure: a call for interdisciplinary care. Eur Heart J Acute Cardiovasc Care. 2015.
64. Hauaji F, Vilella LM, Gonçalves C, Oliveira LC. The Total face mask is more comfortable than the oronasal mask in noninvasive ventilation but is not associated with improved outcome. Respiration. 2011;82:426-30.

65. Carteaux G, Lyazidi A, Cordoba-Izquierdo A, Vignaux L, Jolliet P, Thille AW, et al. Patient-ventilator asynchrony during noninvasive ventilation: a bench and clinical study. Chest. 2012;142:367-76.

66. Lellouche F, L'Her F, Abroug F, Deye N, Rodriguez PO, Rabbat A, et al. Impact of the humidification device on intubation rate during noninvasive ventilation with ICU ventilators: results of a multicenter randomized controlled trial. Intensive Care Med. 2014;40:2119.

67. Hess DR. Patent-ventilator interaction during noninvasive ventilation. Respir Care. 2011;56:153-65.

68. Thille A, Rodriguez P, Cabello B, Lellouche F, Brochard L. Patientventilator asynchrony during assisted mechanical ventilation. Intensive Care Med. 2006;32:1515-22.

69. Vignaux L, Vargas F, Roeseler J, Tassaux D, Thille AW, Kossowsky MP, et al. Patient-ventilator asynchrony during noninvasive ventilation for acute respiratory failure: a multicenter study. Intensive Care Med. 2009;35:840-6.

70. Devlin JW, Nava S, Fong JJ, Bahhady I, Hill NH. Survey of sedation practices during noninvasive positive-pressure ventilation to treat acute respiratory failure. Crit Care Med. 2007;35:2298-302.

71. Matsumoto T, Tomii K, Tachikawa R, Otsuka K, Nagata K, Otsuka $\mathrm{K}$, et al. Role of sedation for agitated patients undergoing noninvasive ventilation: clinical practice in a tertiary referral hospital. BMC Pulm Med. 2015;15:71.

72. Muriel A, Peñuelas O, Frutos-Vivar F, Arroliga AC, Abraira V, Thille AW, et al. Impact of sedation and analgesia during noninvasive positive pressure ventilation on outcome: a marginal structural model causal analysis. Intensive Care Med. 2015;41:1586-600.

73. Conti G, Hill NS, Nava S. Is sedation safe and beneficial in patients receiving NIV? No. Intensive Care Med. 2015;41:1692-5.

74. Hilbert G, Navalesi P, Girault C. Is sedation safe and beneficial in patients receiving NIV? Yes. Intensive Care Med. 2015;41:1688 91

Publisher's Note Springer Nature remains neutral with regard to jurisdictional claims in published maps and institutional affiliations. 